\title{
Enhancement of Photocatalytic Activity of Synthesized ZnO Nanoparticles with Oxygen Plasma Treatment
}

\author{
Sang-Hun Nam ${ }^{1, *}$ and Jin-Hyo Boo ${ }^{1,2, *}$ \\ ${ }^{1}$ Institute of Basic Science, Sungkyunkwan University, Suwon 440-746, South Korea \\ ${ }^{2}$ Department of Chemistry, Sungkyunkwan University, Suwon 440-746, South Korea
}

\begin{abstract}
$\mathrm{ZnO}$ nanoparticles were synthesized by the spray-pyrolysis method. There were exposed to oxygen plasma treatment to increase $\mathrm{OH}$ radicals on their surfaces. $\mathrm{ZnO}$ nanoparticles were spherical grains with a narrow size range of about $7 \sim 10 \mathrm{~nm}$, and these small particles agglomerated together to form larger clusters. Synthesized $\mathrm{ZnO}$ nanoparticles and a p-25 mixed MB solution exposed to UV illustrate that $\mathrm{p}-25$ has a better photo-degradation response than synthesized $\mathrm{ZnO}$ nanoparticles using UV light. Therefore, we did oxygen plasma treatment to increase $\mathrm{OH}$ radicals on the surface of synthesized $\mathrm{ZnO}$ nanoparticles. As a result, the photocatalytic activity of oxygen plasma treated $\mathrm{ZnO}$ nanoparticles was enhanced by about $60 \%$ based on the absorption peak of the decomposed MB solution. Also, we have analyzed the surface of oxygen plasma treated $\mathrm{ZnO}$ nanoparticles by XPS. Results showed that $\mathrm{OH}$ radicals and molecular water on the $\mathrm{ZnO}$ surface are enhanced by oxygen plasma treatment. Also, treatment reduced oxygen and zinc vacancies on the treated $\mathrm{ZnO}$ surface.
\end{abstract}

Keywords: $\mathrm{ZnO}$; Oxygen Plasma; $\mathrm{OH}$ radical; Photocatalyst; X-ray Photoelectron Spectroscopy 
*Contact details of corresponding authors

Name: Dr. Sang-Hun Nam and Jin-Hyo Boo

Postal address: Department of Chemistry and Institute of Basic Science, Sungkyunkwan University, 300 Cheoncheon-dong, Jangan-gu, Suwon 440-746, South Korea

Telephone number: +82-31-299-4124

Fax number: +82-31-290-7075

E-mail address: askaever@gmail.com and jhboo@skku.edu 


\section{Introduction}

In the past few decades, oxide semiconductors have been well known as photocatalysts [1-3] since the Honda-Fujishima effect [4, 5] was reported in the 1970s. They reported a photocatalytic effect in $\mathrm{TiO}_{2}$ wherein water split on the $\mathrm{TiO}_{2}$ electrode. Since then, much research in photocatalysis has been performed with semiconductor oxide materials such as $\mathrm{TiO}_{2}, \mathrm{ZrO}_{2}, \mathrm{SnO}_{2}$ and $\mathrm{ZnO}[1,6,7]$. Zinc oxide is a direct band gap (3.37 eV) semiconductor, which has a hexagonal wurtzite structure. $\mathrm{ZnO}$ is a good candidate for photocatalysis because it has physical and chemical stability, high oxidative properties, and absorbs ultraviolet light. When $\mathrm{ZnO}$ is irradiated by UV light, redox (reduction and oxidation) reactions will occur on the $\mathrm{ZnO}$ surface, generating $\mathrm{O}_{2}^{-}$and $\mathrm{OH}$ radicals. These two powerful oxidizing agents have been proven to be effective in the degradation of harmful organic materials, converting them into $\mathrm{CO}_{2}$ and $\mathrm{H}_{2} \mathrm{O}$. Therefore, we assume that the presence of oxygen on the surface of $\mathrm{ZnO}$ is a very important factor in the photocatalytic activity of $\mathrm{ZnO}$ nanoparticles. Hydroxyl radicals attack the $\mathrm{C}-\mathrm{H}$ bonds of organic compounds to lead to complete mineralization. The effective separation of electron-hole pairs or the enhanced degradation of organic pollutants can be realized by increasing the concentration of electron donors such as surface hydroxyl groups and by the enhanced reduction of adsorbed molecular oxygen. An increase in the concentration of surface hydroxyl groups may be achieved by the addition of foreign metal oxide [8-10]. According to S. K. Lam [11], thermal treatment in air allows more oxygen molecules to be adsorbed on the surface of $\mathrm{TiO}_{2}$. These oxygen molecules act as photoexcited electron traps and inhibit the recombination of photoexcited electrons and holes.

In this study, $\mathrm{ZnO}$ nanoparticles were synthesized by the spray-pyrolysis method and were $\mathrm{O}_{2}$ plasma surface treated to increase $\mathrm{O}_{2}^{-}$or $\mathrm{OH}$ radicals on the surface. We studied the photocatalytic activity of synthesized $\mathrm{ZnO}$ nanoparticles as compared with commercial $\mathrm{TiO}_{2}$

powder (Degussa P-25). Synthesized $\mathrm{ZnO}$ nanoparticles were characterized by scanning 
electron microscopy (SEM), transmittance electron microscopy (TEM), energy dispersive spectrometry (EDS), X-ray diffraction (XRD) and Brunauer-Emmett-Teller (BET) tests. The photocatalytic activity of synthesized-ZnO nanoparticles was evaluated using UV-VIS absorption spectroscopy through degradation of a Methylene Blue (MB) solution. We used Xray photoelectron spectroscopy (XPS) to assess the difference before and after $\mathrm{O}_{2}$ plasma surface treatment.

\section{Experimental details}

$\mathrm{ZnO}$ nanoparticles were synthesized by spray-pyrolysis. A homemade spray-pyrolysis system composed of a furnace, sonication system and temperature controller was used. The synthesis solution was prepared by mixing zinc acetate dehydrate $\left(\mathrm{Zn}\left(\mathrm{CH}_{3} \mathrm{COO}\right)_{2} \cdot 2 \mathrm{H}_{2} \mathrm{O}\right)$ with distilled water to a concentration of $0.5 \mathrm{M}$, followed by stirring for $30 \mathrm{~min}$. This solution was used as the precursor in the synthesis of $\mathrm{ZnO}$ nanoparticles. The solution was sprayed by sonication and flow into a vertical quartz reactor in a furnace at $800{ }^{\circ} \mathrm{C}$ and $900{ }^{\circ} \mathrm{C}$ without carrier gas. The synthesis temperature was maintained for $60 \mathrm{~min}$. Crystal structure was identified by an $\mathrm{X}$-ray diffractometer with $\mathrm{Cu} \mathrm{K}_{1}$ radiation. $\mathrm{O}_{2}$ plasma surface treatment was applied to the synthesized $\mathrm{ZnO}$ nanoparticles using a microwave plasma treatment system at a frequency of 2.45 GHz. $\mathrm{ZnO}$ nanoparticles were exposed to flowing oxygen gas at a power of $300 \mathrm{~W}$ for $300 \mathrm{sec}$ in the microwave plasma system. The working pressure was $250 \mathrm{mTorr}$, and the $\mathrm{O}_{2}$ flux was changed from $20 \mathrm{sccm}$ to $100 \mathrm{sccm}$ in $20 \mathrm{sccm}$ intervals, as noted in Table 1.

A Methylene Blue (MB, $\left.\mathrm{C}_{16} \mathrm{H}_{18} \mathrm{ClN}_{3} \mathrm{~S}\right)$ solution was prepared by dissolving $0.008 \mathrm{~g}$ of $\mathrm{MB}$ in $1000 \mathrm{~mL}$ distilled water, for a concentration of $2.50 \times 10^{-5} \mathrm{M}(\mathrm{mole} / \mathrm{L})$. This MB solution was used as a test for the photocatalytic activity of synthesized $\mathrm{ZnO}$ nanoparticles and commercial $\mathrm{TiO}_{2}$ powder $(\mathrm{P}-25)$. Prepared $\mathrm{ZnO}$ nanoparticles $(1 \mathrm{mg})$ were placed in a $1 \mathrm{~cm} \times$ $1 \mathrm{~cm}$ plastic cuvette and filled with $5 \mathrm{~mL}$ of MB solution. The cuvette was irradiated by UV 
light $(254 \mathrm{~nm})$ in a black box. Photo-degradation was monitored over time using UV-VIS spectroscopy. Specifically, absorption spectra of the degradation of MB in solution were measured at intervals of 10 min for an hour.

\section{Results and Discussion}

Figure 1 shows the SEM images and EDS data which were synthesized $\mathrm{ZnO}$ nanoparticles via spray-pyrolysis metheod at 800 and $900{ }^{\circ} \mathrm{C}$ for $60 \mathrm{~min}$, respectively. We used EDS (Energy Dispersive Spectrometry) to confirm the difference of element ratio of $\mathrm{ZnO}$ nanoparticles. $\mathrm{Zn}: \mathrm{O}$ atomic\% ratio of synthesized $\mathrm{ZnO}$ nanoparticles was about 1:1. Synthesized $\mathrm{ZnO}$ nanoparticles at $800{ }^{\circ} \mathrm{C}$ were had a little more zinc as compared with synthesized $\mathrm{ZnO}$ nanopaticles at $900{ }^{\circ} \mathrm{C}$. Element ratio of synthesized $\mathrm{ZnO}$ nanoparticles at temperature over $800{ }^{\circ} \mathrm{C}$ did not influenced synthesis temperature.

Figure 2 and Table 2 provide physical-chemical properties of synthesized $\mathrm{ZnO}$ nanoparticles. Figure 2(a) shows SEM and TEM images of $\mathrm{ZnO}$ nanoparticle synthesized at $900{ }^{\circ} \mathrm{C}$ for 60 min by spray-pyrolysis. Synthesized $\mathrm{ZnO}$ nanoparticles were approximately $1 \mu \mathrm{m}$ in size and had the shape of crumpled paper. Spray-pyrolysis synthesized materials have fast synthesis rates at high temperature, resulting in the irregular shapes. Synthesized $\mathrm{ZnO}$ nanoparticles were spherical grains with a narrow size range of about $7 \sim 10 \mathrm{~nm}$ based on high resolution TEM images. Also, these small particles were agglomerated together to form larger clusters. Figure 2(b) shows XRD patterns of $\mathrm{ZnO}$ nanoparticles synthesized at $900{ }^{\circ} \mathrm{C}$ for $60 \mathrm{~min}$. The d-spacing values and relative intensities of the peaks coincide exactly with the JCPDS data for pure $\mathrm{ZnO}$, which crystallizes in a hexagonal wurtzite structure. These particles consist of polycrystalline grains and preferential growth was observed. Thus, the spray-pyrolysis synthesis yielded pure $\mathrm{ZnO}$ nanoparticles that have no impurities.

Table 2 provides the mean size of $\mathrm{ZnO}$ nanoparticles synthesized at $900{ }^{\circ} \mathrm{C}$ based on $\mathrm{XRD}$ 
and TEM image data. Also, the surface area of synthesized $\mathrm{ZnO}$ nanoparticles was defined through the Brunauer-Emmett-Teller (BET) method using $\mathrm{N}_{2}$ adsorption at $77 \mathrm{~K}$. The average size of the $\mathrm{ZnO}$ nanoparticles was calculated from the full with at half maximum (FWHM) of the highest intensity peak, (101), according to the Scherrer equation, $\mathrm{t}=\mathrm{k} \cdot \lambda / \mathrm{B} \cdot \cos \theta$, where $\mathrm{k}$ is a constant taken as $0.9, \lambda$ is the wavelength of the $\mathrm{X}$-ray radiation $(\lambda=0.154 \mathrm{~nm}), \theta$ is the diffraction angle and $\mathrm{B}$ is the FWHM of the XRD peak. The average size of the $\mathrm{ZnO}$ nanoparticles was $17.5 \mathrm{~nm}$, based on the Scherrer equation. Thus, particle size calculated from XRD was $10 \mathrm{~nm}$ higher than that observed from the TEM image. Based on this, the size of the particle domains and the actual particle size were not the same.

Figure 3 shows the surface areas of $\mathrm{ZnO}$ nanoparticles before and after oxygen plasma treatment irradiation. Before oxygen plasma irradiation, $\mathrm{ZnO}$ nanoparticles had $44 \mathrm{~m}^{2} / \mathrm{g}$ of surface areas and $0.12 \mathrm{ml} / \mathrm{g}$ of total volume. Also, $\mathrm{ZnO}$ nanoparticles had $43 \mathrm{~m}^{2} / \mathrm{g}$ of surface areas and $0.18 \mathrm{ml} / \mathrm{g}$ of total volume after oxygen plasma irradiation. This result means that oxygen plasma treatment was influenced change of surface functional group but was not change the surface areas.

The photocatalytic activity of synthesized $\mathrm{ZnO}$ nanoparticles was carried out using UV light. A Methlyene Blue (MB) solution was used as a test contaminant since it has been extensively used as an indicator for photocatalytic activities owing to its absorption peaks in the visible range. Figure 4 shows photo-degradation experimental results for $\mathrm{MB}$ with synthesized $\mathrm{ZnO}$ nanoparticles, $\mathrm{TiO}_{2}$ (p-25, Degussa), and $\mathrm{O}_{2}$ treated $\mathrm{ZnO}$ nanoparticle under UV irradiation. The first curve (squares) represents only $\mathrm{MB}$ dissolved in water and shows very small degradation $(6.8 \%)$ when irradiated with UV light. This smaller degradation of MB might be due to the interaction of $\mathrm{MB}$ with $\mathrm{OH}$ radicals in water. The second curve (circles) corresponds to the $\mathrm{MB}$ solution mixed with synthesized $\mathrm{ZnO}$ nanoparticles, while the third curve (triangles) is the $\mathrm{p}-25 / \mathrm{MB}$ solution. As shown, $\mathrm{p}-25$ has better photo-degradation 
response than synthesized $\mathrm{ZnO}$ nanoparticles using UV light. Photocatalytic activity of $\mathrm{ZnO}$ is attributed to both the donor and acceptor states caused by the large number of defect sites from oxygen or zinc vacancies [12]. However, lower photo-degradation of MB with UV and synthesized $\mathrm{ZnO}$ nanoparticles may be caused by a small amount of oxygen or zinc vacancies. We presume that this lower photo-degradation may be due to the faster recombination of electron-hole pairs or a decrease in $\mathrm{OH}$ radical. Therefore, oxygen plasma treatment was performed to increase $\mathrm{OH}$ radicals on the synthesized $\mathrm{ZnO}$ nanoparticle surface, as shown in Table 1.

Plasma surface treatment has been investigated by many researchers for the purpose of modifying surfaces $[13,14]$. Microwave surface $\mathrm{O}_{2}$ plasma treatment was used to introduce oxygen into the surface of synthesized $\mathrm{ZnO}$ nanoparticles. The $\mathrm{O}_{2}$ gas flux was increased gradually in increments of $20 \mathrm{sccm}$ from $20 \mathrm{sccm}$ up to $100 \mathrm{sccm}$. After that, the absorption spectrum of the $\mathrm{MB}$ solution with the $\mathrm{O}_{2}$ plasma treated- $\mathrm{ZnO}$ nanoparticles was measured by UV-Vis spectroscopy. The photocatalytic activity of synthesized $\mathrm{ZnO}$ nanoparticles was enhanced for $\mathrm{O}_{2}$ plasma treated samples. The photo-degradation rate of $\mathrm{MB}$ with $\mathrm{O}_{2}$ treated $\mathrm{ZnO}$ nanoparticles irradiated with UV light was much faster than non-treated $\mathrm{ZnO}$ nanoparticles irradiated with UV light, as shown in Figure 4. It took only 15 min for $\mathrm{O}_{2}$ treated $\mathrm{ZnO}$ to decolorize $50 \%$ of the $\mathrm{MB}$ while, for non-treated $\mathrm{ZnO}$, it took more than 40 min. This faster degradation rate of $\mathrm{MB}$ is attributed to increased $\mathrm{OH}$ radicals. Also, we assume that faster photo-degradation effects may be due to decreased recombination of electron-hole pairs.

We were checking the change of $\mathrm{O}-\mathrm{H}$ stretching peak after photocatalytic reaction via FT-IR spectrum in figure 5. O-H stretching peak was increased on the $\mathrm{ZnO}$ nanoparticles surface by oxygen plasma treatment. Also, O-H stretching peak has decreased after photocatalytic reaction. This trend is similar to the photocatalytic efficiency. 
We had researched $\mathrm{ZnO}$ and $\mathrm{TiO}_{2}$ nanoparticles before/after oxygen plasma treatment for improvement of photocatalytic activity in figure 6. After oxygen plasma treatment, $\mathrm{ZnO}$ and $\mathrm{TiO}_{2}$ nanaoparticles had photocatalytic activity enhancement. However, $\mathrm{TiO}_{2}$ nanoparticles had not maintained improved photocatalytic activity at repeated reaction. By comparison, oxygen treated $\mathrm{ZnO}$ nanoparticles maintained the improved photocatalytic activity. This is a very important point and because of this, we used a $\mathrm{ZnO}$ material.

We examined photocatalytic activity of $\mathrm{ZnO}$ nanoparticles in repeated reactions. Figure 7 shows the photocatalytic activity of oxygen plasma treated $\mathrm{ZnO}$ nanoparticles in repeated reactions. Photocatalytic activity of oxygen plasma treated $\mathrm{ZnO}$ nanoparticles steadily decreased over the 10 times of recurrent reaction. The initial photocatalytic efficiency is decreased by approximately $8 \%$ and the final photocatalytic efficiency was reduced by about 10\%. This result means that photocatalytic activity was maintained consistently for reabsorption of $-\mathrm{OH}$ radical and molecular water in methyleneblue solution.

Figure 8 show that EPR (Electron Paramagnetic Resonance) spectrum confirmed the correlation between changes in photocatalytic activity and changes in $\mathrm{O}_{2}{ }^{-}$(superoxide) groups after water treatment. The $\mathrm{g}$ factor was calculated via: $\Delta \mathrm{E}=h v=g \cdot \mu_{B} \cdot B_{0}$, where $h$ is the Planck constant, $v$ the microwave frequency, $g$ the $\mathrm{g}$ factor, $\mu_{B}$ the Bohr magnetron, and $B_{0}$ the magnetic field, respectively. For EPR measurements, the microwave frequency was 9.648 GHz. Thus, the calculated g factor was 1.96 for samples with $\mathrm{O}_{2}{ }^{-}$(superoxide). In Figure 8, before/after oxygen plasma treated $\mathrm{ZnO}$ nanoparticles had a $\mathrm{g}$ factor of 1.96 with $\mathrm{O}_{2}{ }^{-}$ (superoxide). However, the intensity of the EPR spectrum did not change, indicating that $\mathrm{O}_{2}{ }^{-}$ is not an important factor in photocatalytic activity.

We used X-ray electron spectroscopy (XPS) to assess the difference before and after the $\mathrm{O}_{2}$ plasma surface treatment. The core level of $\mathrm{Zn} 2 \mathrm{p}$ spectra shows similar features in both the untreated and oxygen treated $\mathrm{ZnO}$ nanoparticles. Figure 9(a) shows the XPS data of $\mathrm{Zn} 2 \mathrm{p}$ in 
synthesized $\mathrm{ZnO}$ nanoparticles before and after $\mathrm{O}_{2}$ plasma treatment. On the surface, $\mathrm{Zn} 2 \mathrm{p}$ core level peaks were shifted to a high binding energy region from $1022.6 \mathrm{eV}$ to $1023.1 \mathrm{eV}$. This result means that synthesized $\mathrm{ZnO}$ nanoparticles change from $\mathrm{ZnO}$ containing metallic zinc to more oxygen-rich zinc. Figure 9(b) shows the $\mathrm{O}$ 1s spectra of synthesized $\mathrm{ZnO}$ nanoparticles before and after $\mathrm{O}_{2}$ plasma treatment. The broad shoulder at the higher binding energy side of the main $\mathrm{O}$ 1s peak of $\mathrm{ZnO}$ nanoparticles before $\mathrm{O}_{2}$ treatment can be fitted with two peaks at 533.1 and $534.1 \mathrm{eV}$, respectively. These two peaks match the physically absorbed $\mathrm{OH}$ radical at $533.1 \mathrm{eV}$ and molecular water at $534.1 \mathrm{eV}$. According to the results of thermal desorption spectroscopy (TDS) by Zwicher and Jacobi [15], the adsorption of molecular water on $\mathrm{ZnO}$ is quite complex. The shoulder peak increased noticeably and intensity increased in fitted peaks, indicating that both the chemisorption and physisorption of $\mathrm{OH}$ radicals and molecular water on the $\mathrm{ZnO}$ surface are enhanced by $\mathrm{O}_{2}$ plasma treatment. Figure 9(c) shows the XP spectra of O 1s peak in the range of 530 to $537 \mathrm{eV}$. Oxygen plasma treatment process was increased peaks that are formed from $\mathrm{OH}$ radical and molecular water at the same time. The oxygen plasma treatment has affected not only increasing of $\mathrm{OH}$ radical, but $\mathrm{ZnO}$ surface adsorption of molecular water in the air as well. Also, $\mathrm{OH}$ radicals and molecular water groups decomposed the MB solution by cracking double bonds $(\mathrm{C}=\mathrm{N}, \mathrm{C}=\mathrm{S})$, and coupling with the $\mathrm{N}-\mathrm{H}$ single bond of the MB solution.

\section{Conclusion}

In this study, $\mathrm{ZnO}$ nanoparticles were synthesized by the spray-pyrolysis method at $900{ }^{\circ} \mathrm{C}$ for $60 \mathrm{~min}$ and were exposed to $\mathrm{O}_{2}$ plasma treatment to increase $\mathrm{OH}$ radicals on their surfaces. Synthesized $\mathrm{ZnO}$ nanoparticles were spherical grains with a narrow size range of about 7 10 $\mathrm{nm}$, and these small particles agglomerated together to form larger clusters. Synthesized $\mathrm{ZnO}$ nanoparticles and a p-25 mixed MB solution exposed to UV illustrate that p-25 has a better 
photo-degradation response than synthesized $\mathrm{ZnO}$ nanoparticles using $\mathrm{UV}$ light. Therefore, we did oxygen plasma treatment to increase $\mathrm{OH}$ radicals on the surface of synthesized $\mathrm{ZnO}$ nanoparticles. As a result, the photocatalytic activity of $\mathrm{O}_{2}$ plasma treated $\mathrm{ZnO}$ nanoparticles was enhanced by about $60 \%$ based on the absorption peak of the decomposed MB solution. Also, we have analyzed the surface of $\mathrm{O}_{2}$ plasma treated $\mathrm{ZnO}$ nanoparticles by XPS. Results showed that $\mathrm{OH}$ radicals and molecular water on the $\mathrm{ZnO}$ surface are enhanced by $\mathrm{O}_{2}$ plasma treatment. Also, treatment reduced oxygen and zinc vacancies on the treated $\mathrm{ZnO}$ surface.

Acknowledgments: This work was supported by the Technology Innovation Program (No. 10046532) of the Korea Evaluation Institute of Industrial Technology (KEIT) grant funded by the Korea government Ministry of Trade, Industry and Energy. Also, this work was supported by Mid-career Researcher Program (2015R1A2A2A01007150) through NRF grant funded by the MEST. 


\section{References}

[1] M. R. Hoffmann, S. T. Martin, W. Choi, D. W. Bahnemann, Chem. Rev. 95 (1995) 69-96.

[2] A. Mills, S. L. Hunte, J. Photochem. Photobiol. A 108 (1997) 1-35.

[3] A. L. Linsebigler, G. Lu, J. T. Yates, Chem. Rev. 95 (1995) 735-758.

[4] A. Fujishima, K. Honda, Nature 238 (1972) 37-38.

[5] W. Kubo, T. Tatsuma, J. Am. Chem. Soc. 128 (2006) 16034-16035.

[6] K. Vinodgopal, P. V. Kamat, Environ. Sci. Technol. 29 (1995) 841-845.

[7] C. Wang, J. Zhao, X. Wang, B. Mai, G. Sheng, P. Peng, J. Fu, Appl. Catal. B 39 (2002) 269-279.

[8] X. Fu, L. A. Clark, Q. Yang, M. A. Anderson, Environ. Sci. Technol. 30 (1996) 647-653.

[9] C. Anderson, A. J. Bard, J. Phys. Chem. 99 (1995) 9882-9885.

[10] C. D. Jaeger, A. J. Bard, J. Phys. Chem. 83 (1979) 3146-3152.

[11] J. C. Yu, J. Lin, D. Lo, S. K. Lam, Langmuir 16 (2000) 7304-7308.

[12] F. Tuomisto, K. Saarinen, D. C. Look, G. C. Farlow, Phys. Rev. 72 (2005) 085206.

[13] B. Olander, A. Wirsén, A. C. Albertsson, Biomacromolecules 3 (2002) 505-510.

[14] E. R. Park, H. K. Jang, E. K. Kang, C. E. Lee, Mater. Res. Bull. 41 (2006) 536-540.

[15] G. Zwicker, K. Jacobi, Surf. Sci. 131 (1983) 179-194. 


\section{Figure captions}

Figure 1. SEM images and EDS data were synthesized $\mathrm{ZnO}$ nanoparticles at 800 and $900{ }^{\circ} \mathrm{C}$ for 60 min via spray-pyrolysis method.

Figure 2. (a) SEM surface morphology and high resolution TEM image of $\mathrm{ZnO}$ nanoparticles synthesized at $900{ }^{\circ} \mathrm{C}$ for $60 \mathrm{~min}$ by spray-pyrolysis and (b) XRD patterns of synthesized $\mathrm{ZnO}$ nanoparticles.

Figure 3. Surface areas of $\mathrm{ZnO}$ nanoparticles before/after oxygen plasma treatment irradiation.

Figure 4. Photoreduction of MB with respect to time using the MB only solution, synthesized $\mathrm{ZnO}, \mathrm{TiO}_{2}$ powder (Degussa, $\mathrm{p}-25$ ) and oxygen plasma treated $\mathrm{ZnO}$ exposed to UV light.

Figure 5. (a) FT-IR high resolution spectrum of $\mathrm{O}-\mathrm{H}$ stretching peak before/after photocatalytic reaction.

Figure 6. Photocatalytic activity test of $\mathrm{ZnO}$ and $\mathrm{TiO}_{2}$ nanoparticles in repeated reaction.

Figure 7. Photocatalytic activity of oxygen plasma treated $\mathrm{ZnO}$ nanoparticles in 10 time s of repeated reactions.

Figure 8. EPR spectrum of $\mathrm{ZnO}$ nanoparticles; (a) untreated, (b) oxygen plasma treated.

Figure 9. Changes in XPS spectra of $\mathrm{ZnO}$ in the (a) $\mathrm{Zn} 2 \mathrm{p}$, (b) $\mathrm{O} 1 \mathrm{~s}$ peak and (c) $\mathrm{OH}$ and $\mathrm{H}_{2} \mathrm{O}$ peaks in $\mathrm{O} 1 \mathrm{~s}$ regions before and after $\mathrm{O}_{2}$ plasma treatment. 
Table captions

Table I. Oxygen plasma treatment conditions for the surface modification of synthesized $\mathrm{ZnO}$ nanoparticles by microwave plasma system.

\begin{tabular}{ccccc}
\hline \multicolumn{4}{c}{$\mathrm{O}_{2}$ plasma treatment conditions } \\
\hline $\begin{array}{c}\text { Microwave } \\
\text { frequency }\end{array}$ & $\mathrm{O}_{2}$ flux & Power & Treatment & Working \\
$\mathbf{2 . 4 5} \mathrm{GHz}$ & $20 \sim 100 \mathrm{sccm}$ & $300 \mathrm{~W}$ & time & pressure \\
\hline
\end{tabular}

Table II. Particle size by XRD, TEM data and surface area of synthesized $\mathrm{ZnO}$ nanoparticles at $900{ }^{\circ} \mathrm{C}$ for $60 \mathrm{~min}$.

\begin{tabular}{cccc}
\hline Syn. Temp. & $\begin{array}{c}\text { Particle size by } \\
\text { XRD data (PS-1) }\end{array}$ & $\begin{array}{c}\text { Particle size by } \\
\text { TEM data (PS-2) }\end{array}$ & Surface area \\
\hline $900^{\circ} \mathrm{C}$ & $17.5 \mathrm{~nm}$ & $8.5 \mathrm{~nm}$ & $43 \mathrm{~m}^{2} / \mathrm{g}$ \\
\hline
\end{tabular}



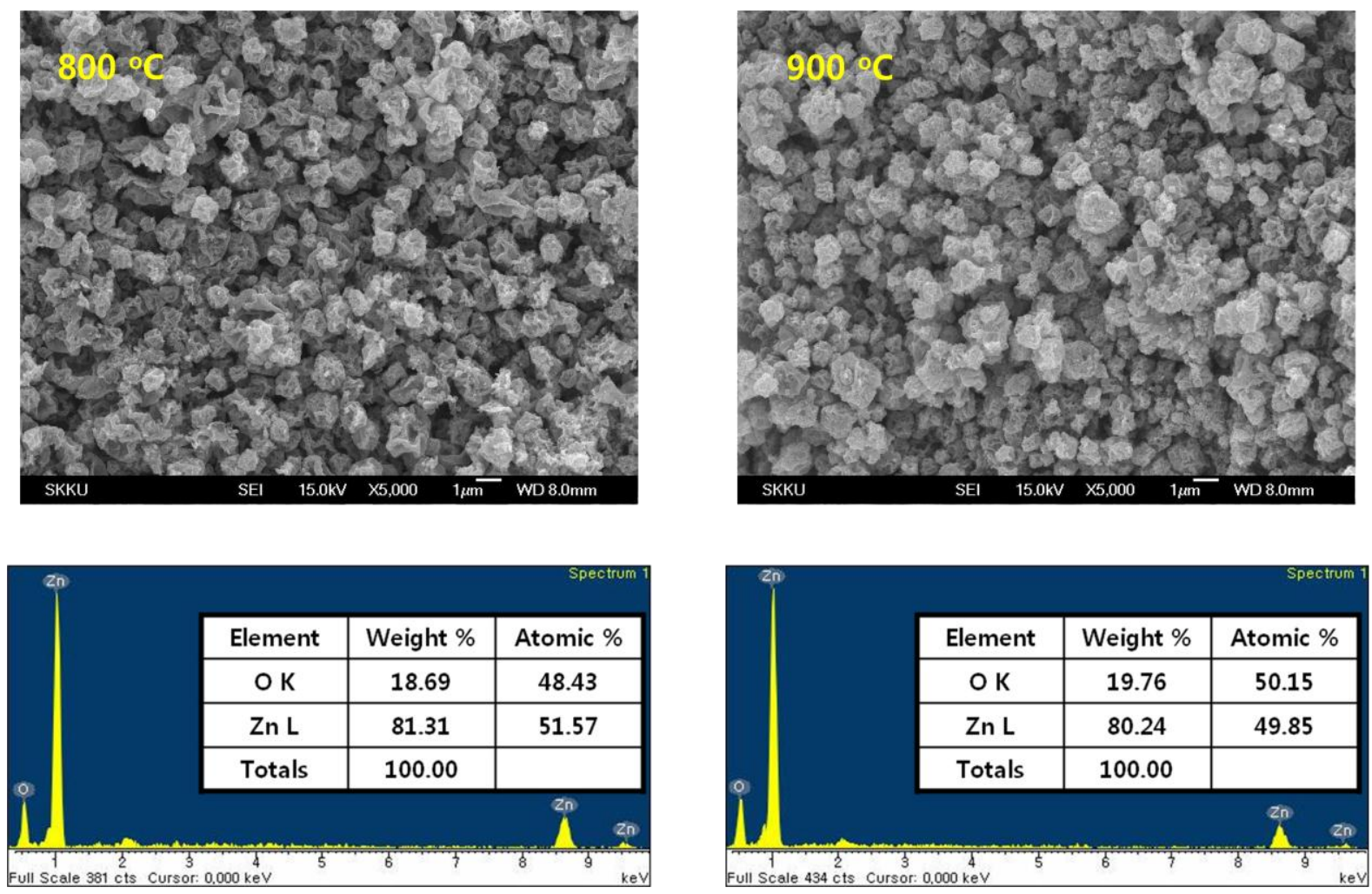

Fig. 1 

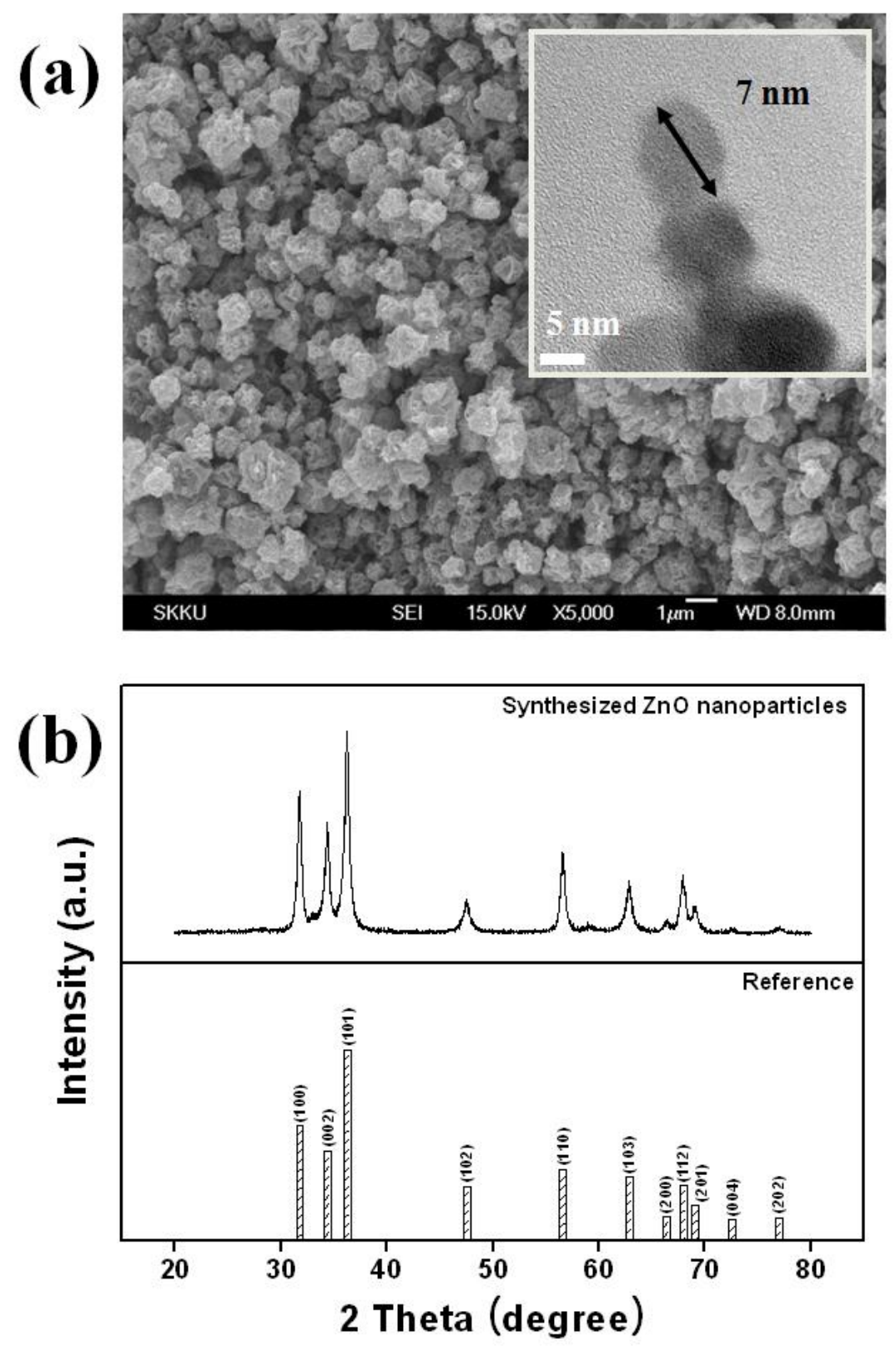

Fig. 2 

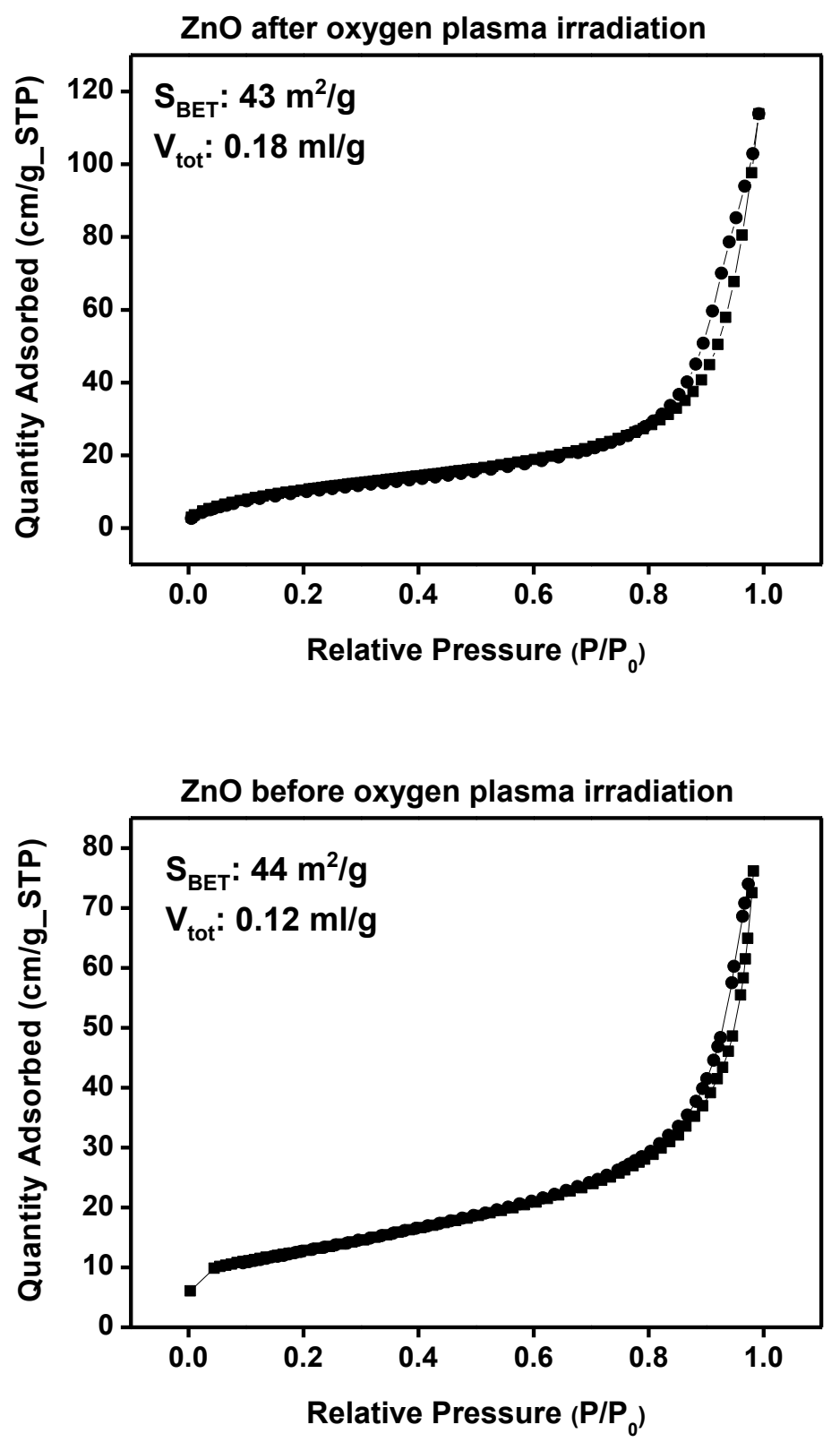

Fig. 3 


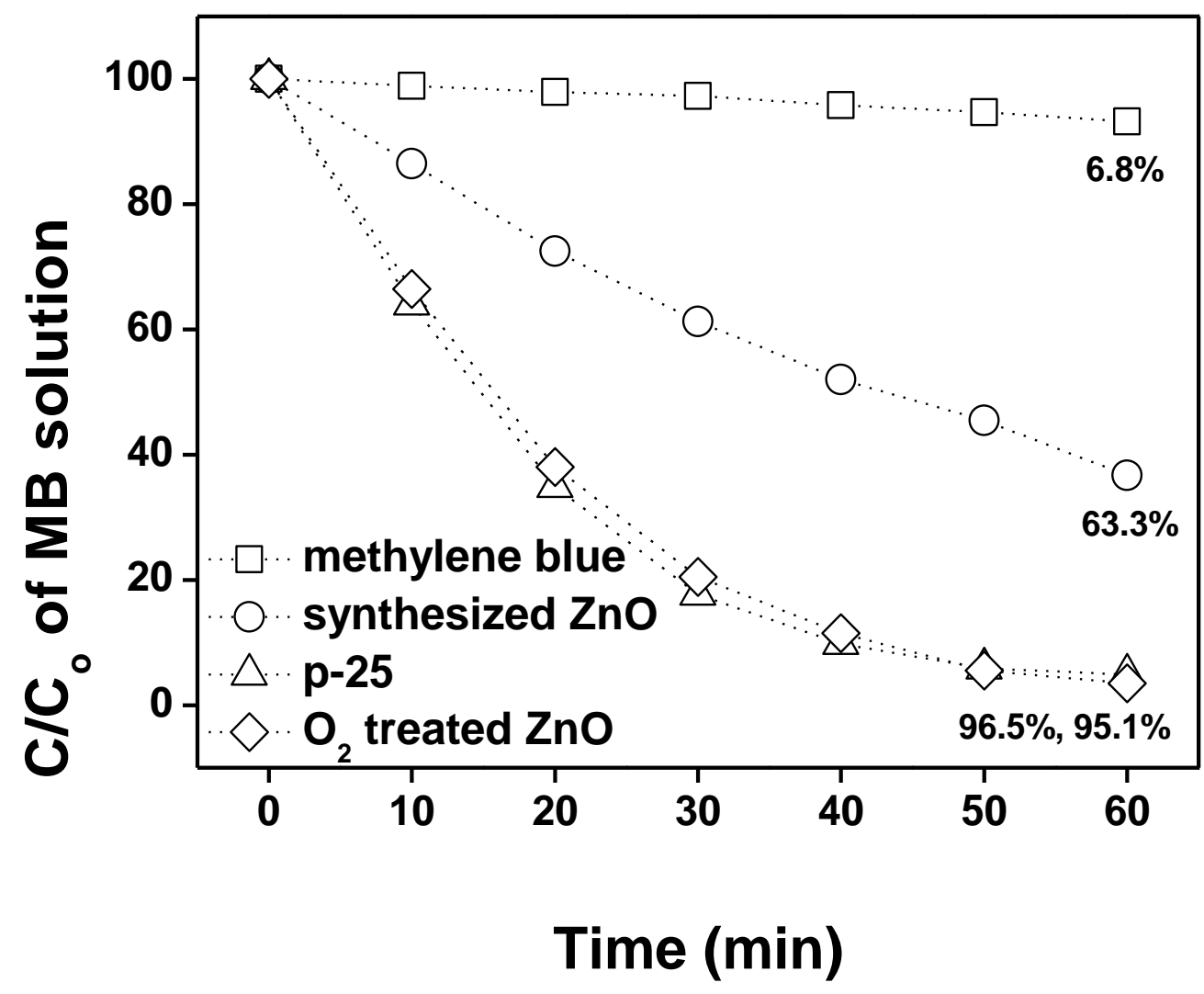

Fig. 4 


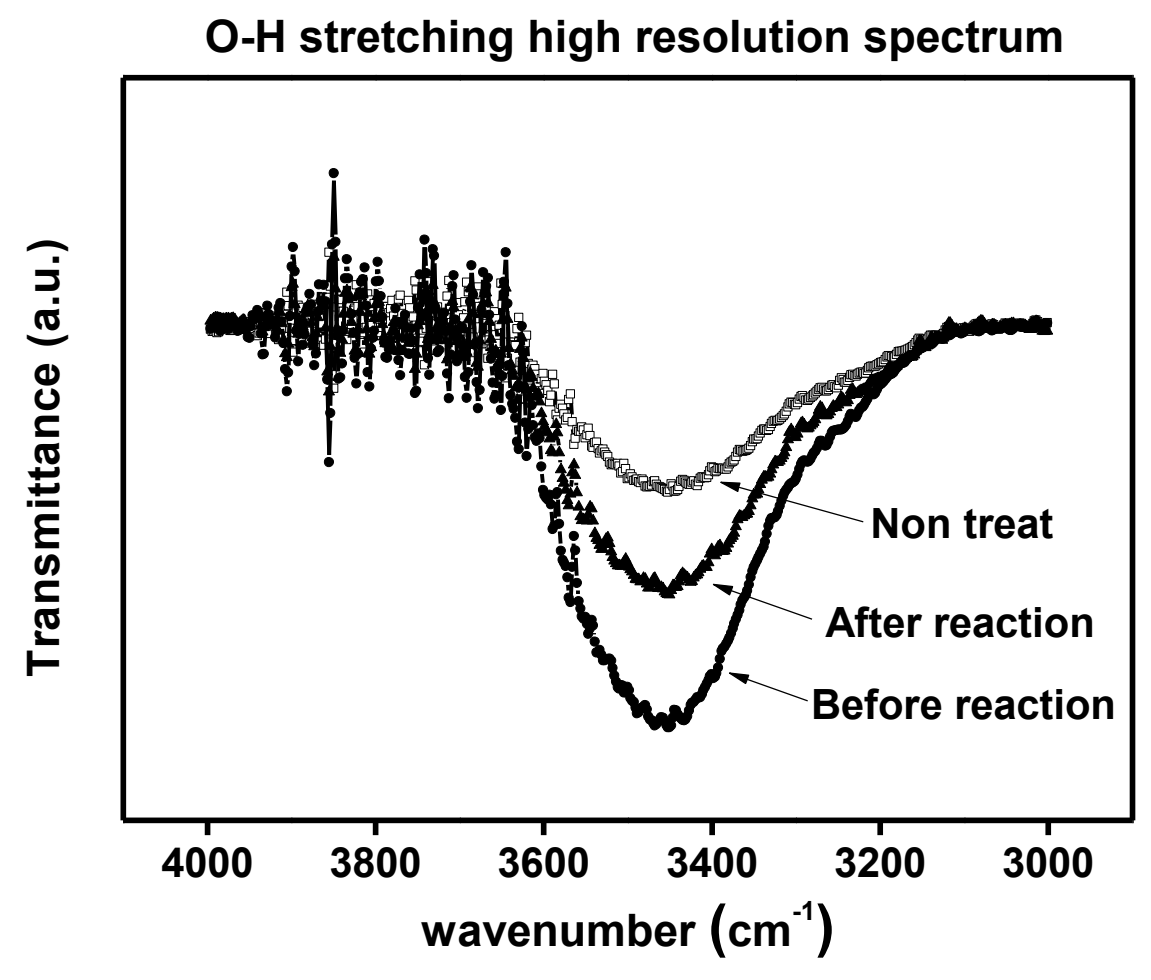

Fig. 5 


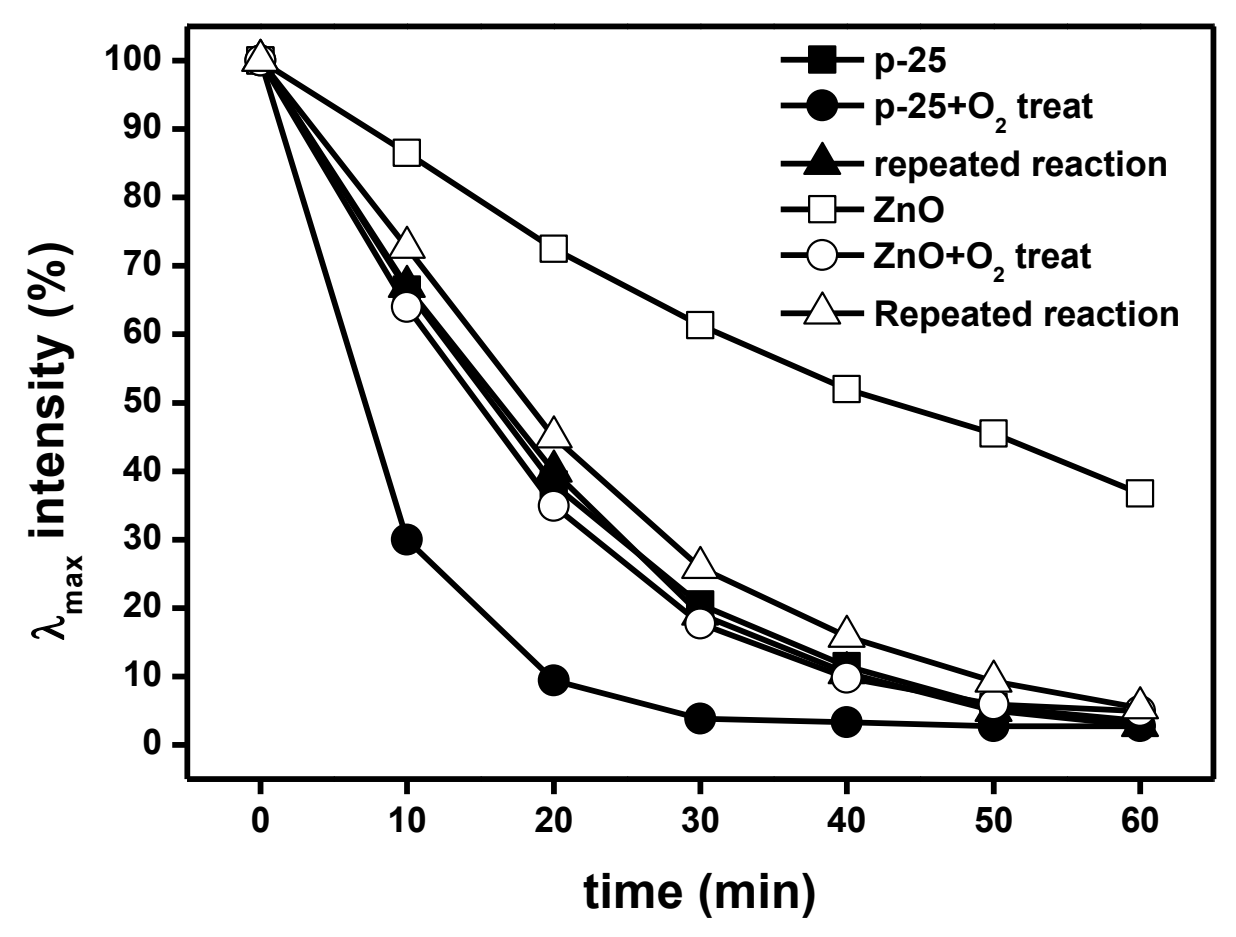

Fig. 6 


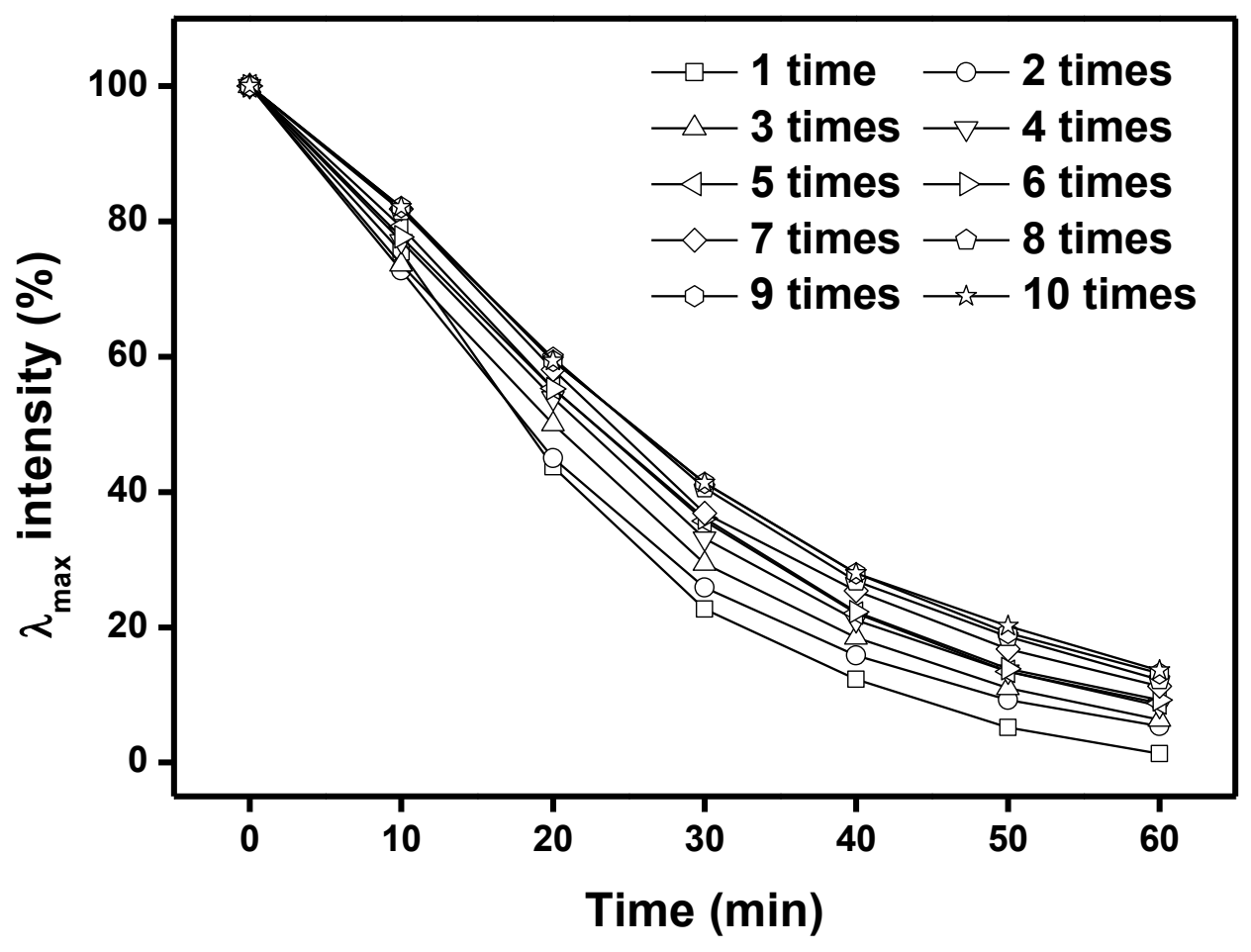

Fig. 7 

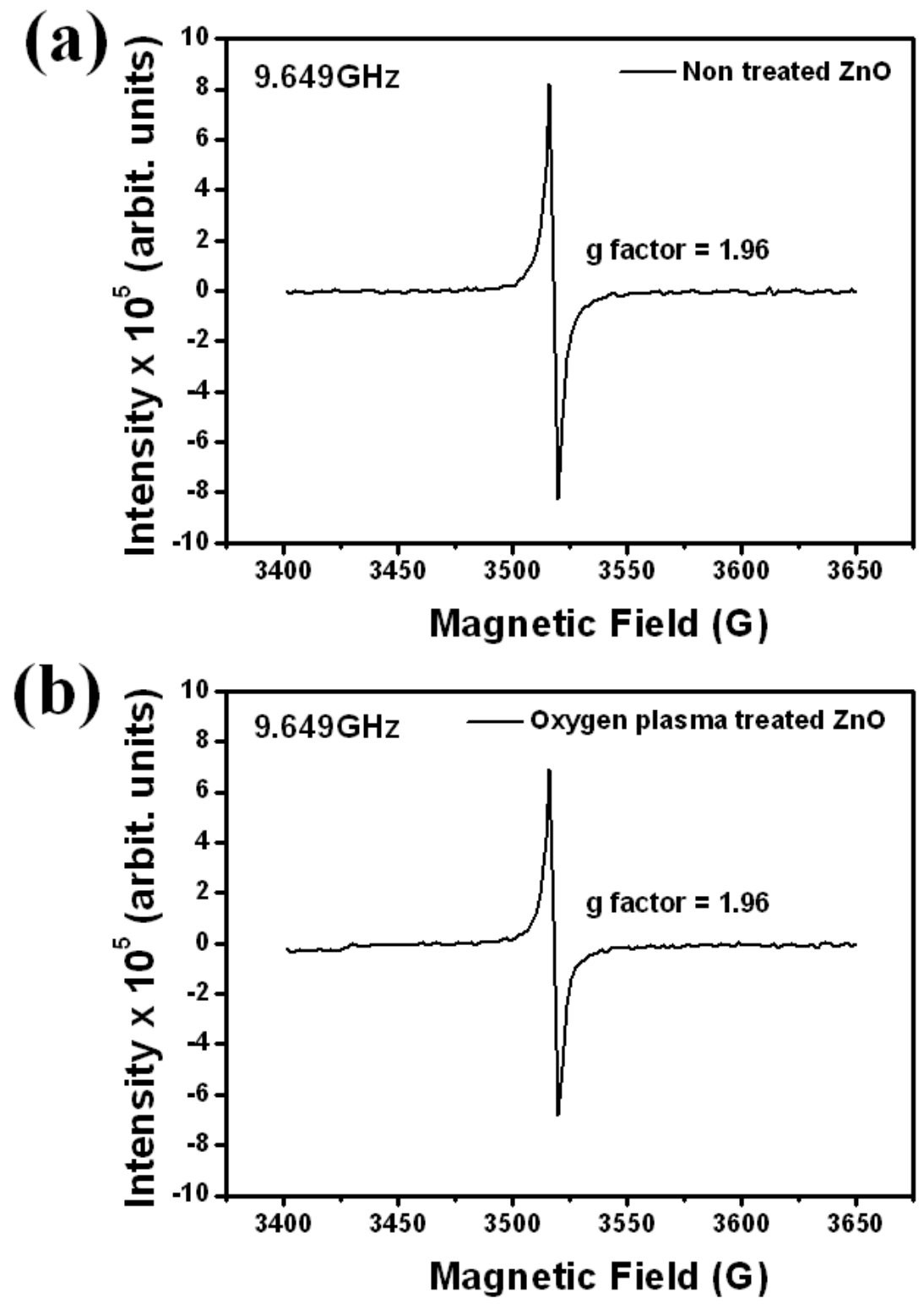

Fig. 8 

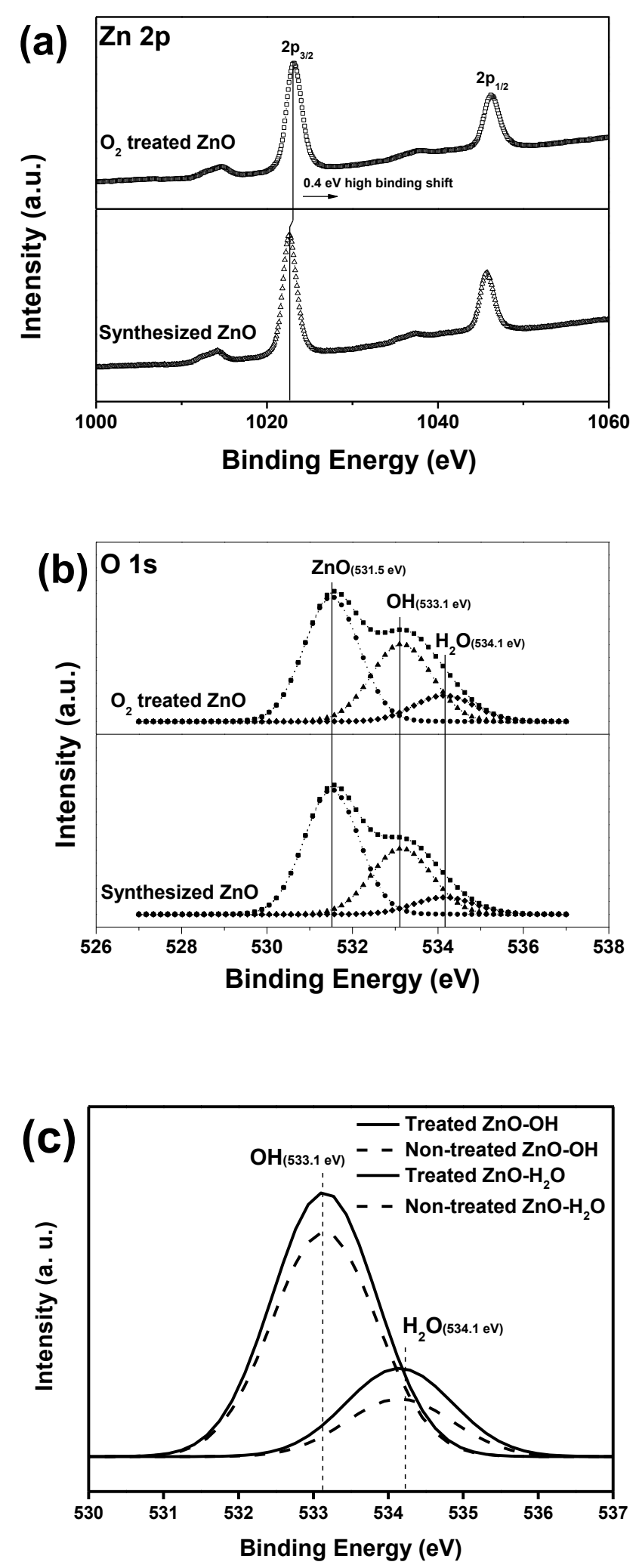

Fig. 9 


\title{
Graphical Abstract
}

\section{Enhancement of Photocatalytic Activity of Synthesized ZnO}

\section{Nanoparticles with Oxygen Plasma Treatment}

\author{
Sang-Hun Nam ${ }^{1, *}$ and Jin-Hyo Boo ${ }^{1,2}$
}

${ }^{1}$ Institute of Basic Science, Sungkyunkwan University, Suwon 440-746, South Korea

${ }^{2}$ Department of Chemistry, Sungkyunkwan University, Suwon 440-746, South Korea

\section{ZnO nanoparticles}

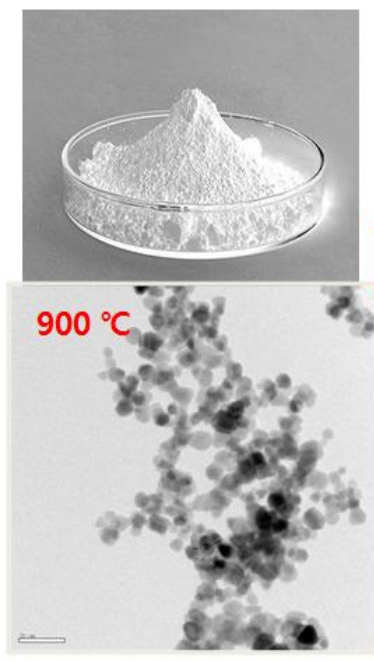

\section{Photocatalytic activity}

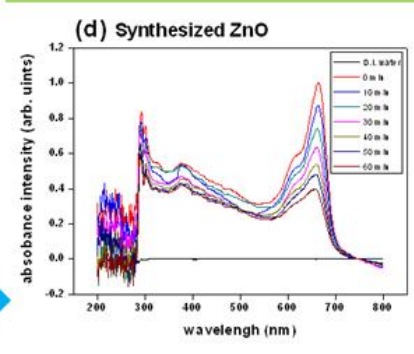

(e) Synthesized $\mathrm{ZnO}_{2}$ treatment

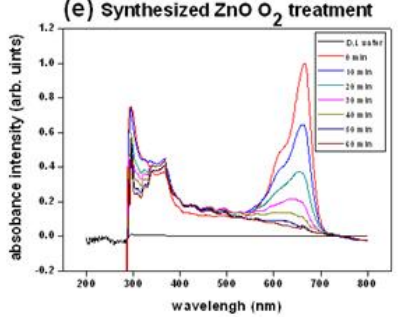

